\title{
A New Species of the Genus Caminus (Astroporida: Geodiidae) from Korea
}

\author{
Eun Jung Shim ${ }^{1, *}$, Chung Ja Sim² \\ ${ }^{1}$ Natural History Museum of Hannam University, Daejeon 306-791, Korea \\ ${ }^{2}$ Department of Biological Sciences, College of Life Sciences and Nano Technology, \\ Hannam University, Daejeon 305-811, Korea
}

\begin{abstract}
Caminus jejuensis n. sp was collected from depth of $20 \mathrm{~m}$ at Geomeunyeo, Seogwipo, Jejudo Island by a SCUBA diving from April 2004 to December 2008. This new species is similar to C. chinensis from China in the composition of spicules except for the spherasters and they differ in spicule size and growth form. This species has longer orthotriaenes and spherules, smaller sterrasters and oxyasters than those of $C$. chinensis. This species also has many spherasters in choanosome, but $C$. chinensis lacks. Morever, the new species is a massive shape with wrinkles, whereas $C$. chinensis is a club shape with smooth surface. Description and figures of the new species are provided.
\end{abstract}

Keywords: Geodiidae, Caminus, new species, Jejudo Island, Korea

\section{INTRODUCTION}

The genus Caminus within family Geodiidae has a single article oscule at the top of the sponge body, and sievelike inhalant pores. The megascleres are consisted of oxeas, strongyles and orthoreiaenes. And also, the microscleres composed of subspherical sterrasters and spherules in cortex and oxyasters in choanosome (Hooper and van Soest, 2002). Up to now, 5 species have been reported in the world (Schmidt, 1862; Sollas, 1886; Lindgren, 1897; Tanita, 1969; PulitzerFinali, 1996). Among them, only one species has been reported from the Korean waters (Sim and Byeon, 1991).

Specimens were collected from depth of $20 \mathrm{~m}$ at Jejudo Island by a SCUBA diving from April 2004 to December 2008. They were preserved in $95 \%$ ethanol and then deposited in the Natural History Museum of Hannam University (HUNHM). The colour and texture were described before preservation. Identification was based on the morphological characteristics, skeletal structure, shape and size of spicules. Skeletal structure and spicules were examined by using microscopy and scanning electron microscopy (SEM). Length and width of 20 spi- cules were measured for each spicule type. Procedure of dissociated spicules followed Rützler (1978).

\section{SYSTEMATIC ACCOUNTS}

Order Astrophorida Sollas, 1888

Family Geodiidae Gray, 1867

Genus Caminus Schmidt, 1862

${ }^{1 *}$ Caminus jejuensis n. sp (Table 1, Figs. 1, 2)

Type specimen. Korea: Holotype (Por. 108), Geomeunyeo, Seogwipo, Jejudo Island, 16 Apr 2004, Lee KJ, by SCUBA diving at 20 m deep, HUNHN. Paratype (Por. 108-1, 108-2), Geomeunyeo, Seogwipo, Jejudo Island, 19 Dec 2008, Kim BI, by SCUBA diving at $20 \mathrm{~m}$ deep, HUNHM.

Description. Massive shape with thick wrinkles, sized up to $5 \times 4 \times 3.5 \mathrm{~cm}$. Oscule $1-3 \mathrm{~mm}$ diameters, rarely scattered. Surface wrinkles. Texture very hard, due to a layer of sterrasters and spherules. Colour khaki in life, gradually changed

Korean name: ${ }^{1 *}$ 제주카미너스해면 (신칭)

(c) This is an Open Access article distributed under the terms of the Creative Commons Attribution Non-Commercial License (http://creativecommons.org/ licenses/by-nc/3.0/) which permits unrestricted non-commercial use, distribution, and reproduction in any medium, provided the original work is properly cited.

pISSN 2234-6953 eISSN 2234-8190
*To whom correspondence should be addressed

Tel: 82-42-629-8455, Fax: 82-42-629-8280

E-mail: hyny1999@hanmail.net 

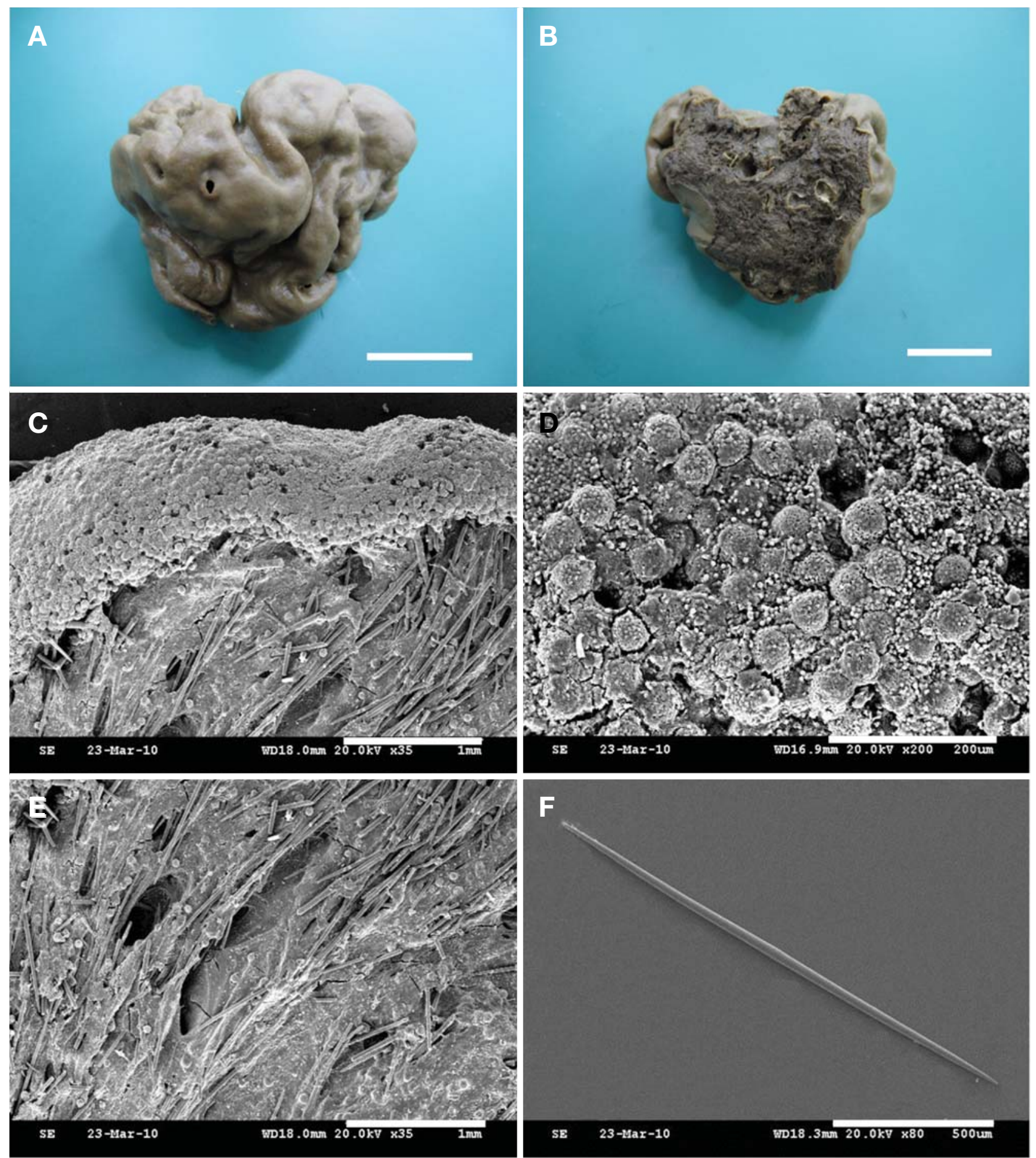

Fig. 1. Caminus jejuensis n. sp. A, Entire animal (upper); B, Entire animal (back); C, Skeleton; D, Cortex; E, Choanosome; F, Oxea. Scale bars: $A, B=1 \mathrm{~cm}, C, E=1 \mathrm{~mm}, D=200 \mu \mathrm{m}, F=500 \mu \mathrm{m}$.

to brown in alcohol. Cortex $1 \mathrm{~mm}$ thick, easily separated from choanosome, densely packed with sterrasters and spherules. Choanosome arranged with oxeas and orthotriaenes. Clads of orthotriaenes faced to cortex and rhabds faced inwards. Oxyasters and spherasters scattered in sponge body.

Spicules. Megascleres oxeas and orthotriaenes. Microscle- 

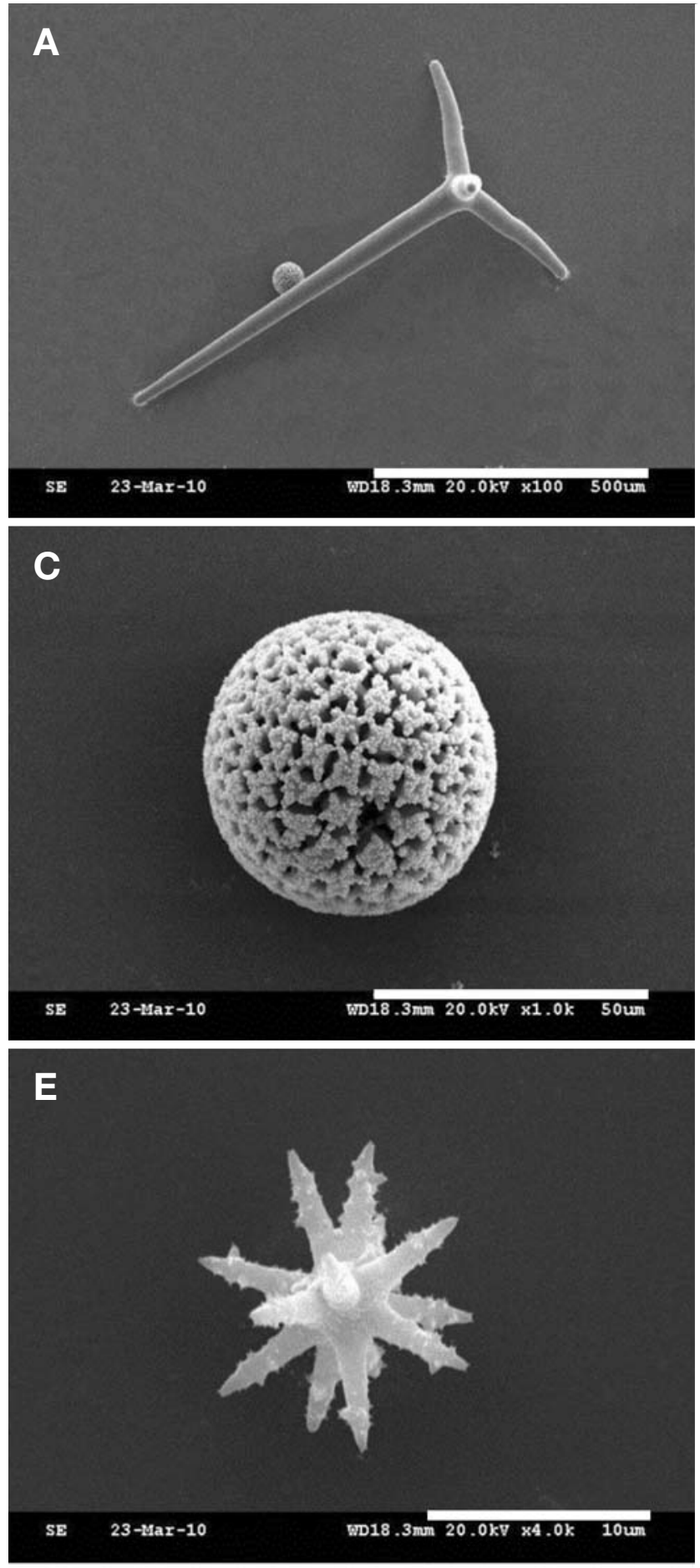
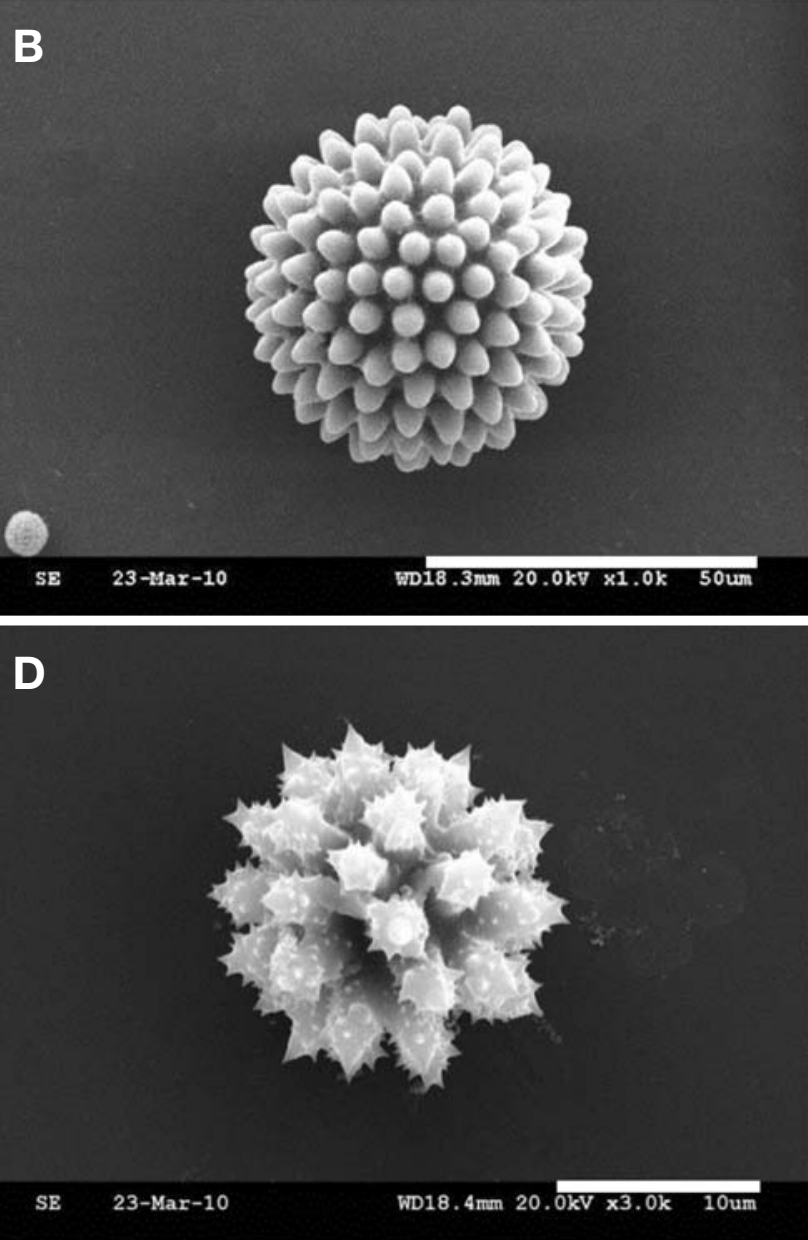

$\mathbf{F}$

Fig. 2. Caminus jejuensis n. sp. A, Orthotriaene; B, C, Sterrasters; $D$, Spheraster; $E$, Oxyaster; $F$, Spherule. Scale bars: $A=500 \mu m$, $B, C=50 \mu \mathrm{m}, D-F=10 \mu \mathrm{m}$.

res sterrasters, spherasters, oxyasters and spherules. Sterrasters round shaped with flat asterose and horn shaped projections at surface. Oxyasters and oxyspherasters spines at ray. Sphe- rules spines on surface.

Etymology. This species is named after the type locality, Jejudo Island, Korea. 
Table 1. Comparison of spicules between Caminus jejuensis $\mathrm{n}$. sp. and $C$. chinensis

\begin{tabular}{lcc}
\hline \multirow{2}{*}{ Spicules $(\mu \mathrm{m})$} & \multicolumn{2}{c}{ Species } \\
\cline { 2 - 3 } & C. jejuensis $\mathrm{n} . \mathrm{sp}$ & C. chinensis \\
\hline Oxeas & $840-1,500 \times 10-30$ & $720 \times 24$ \\
Orthotriaenes & Rhabds $350-1,060 \times 20-50$ & Rhabds $460-600 \times 36$ \\
& Clads $150-300$ & Clads $325-540$ \\
Sterrasters & $40-60$ & 136 \\
Spherasters & $15-23$ & - \\
Oxyasters & $7-15$ & $24-32$ \\
Spherules & $4-10$ & $2-5$ \\
\hline
\end{tabular}

Remarks. This new species is similar to Caminus chinensis from China (Lindgren, 1897) in the composition of spicules except for the spherasters. They differ in the spicule size and growth form. This species has longer orthotriaenes and spherules, smaller sterrasters and oxyasters than those of $C$. chinensis. This species also has many spherasters in choanosome, but $C$. chinensis lacks (Table 1). Morever, the new species is a massive shape with wrinkles, whereas $C$. chinensis is a club shape with smooth surface.

\section{ACKNOWLEDGMENTS}

This research was supported by a grant from Marine Biotechnology Programme funded by the Ministry of Land, Transport and Maritime Affairs of Korean Government. We thank Dr. G.J. Bakus in the Department of Biological Science, University of Southern California for his review and manuscript.

\section{REFERENCES}

Hooper JNA, van Soest RWM, 2002. Systema Porifera: a guide to the classification of sponges. Kluwer Academics/Pleum Publisher Press, New York, pp. 1-1101.

Lindgren NG, 1897. Beitrag zur Kenntniss der Spongienfauna des Malaiischen Archipels und der Chinesischen Meere. Zoologische Anzeiger, 547:480-487.

Pulitzer-Finali G, 1996. Sponges from the Bismarck Sea. Bollettino dei Musei e degli Instituti Biologici della (R.) Università di Genova, 60-61:101-138.

Rützler K, 1978. Sponges in coral reef. In: Coral reef: research method. Monographs on oceanographic methodology 5 (Eds., Stoddart DR, Johannes RE). United Nations Educational, Scientific and Cultural Organization, Paris, pp. 299-313.

Schmidt O, 1862. Die Spongien des adriatischen Meeres. Wilhelm Engelmann, Leipzig, pp. 1-88.

Sim CJ, Byeon HS, 1991. A systematic study on the marine sponges from the South sea of Korea: three new record for Korea. Korean Journal of Systematic Zoology, 7:111-116.

Sollas WJ, 1886. Preliminary account of the tetractinellid sponges dredged by H.M.S. 'Challenger' 1872-76. Part I. The Choristida. Scientific Proceedings of the Royal Dublin Society (new series), 5:177-199.

Tanita S, 1969. Further studies on the sponges obtained from the Sado Island and its adjacent waters. Bulletin Japan Sea Regional Fisheries Laboratory, 21:67-88. 